Article

\title{
Bibliometric Analysis of Global Remote Sensing Research during 2010-2015
}

\author{
Hongyue Zhang ${ }^{1}$, Mingrui Huang ${ }^{1}$, Xiuling Qing ${ }^{2}$, Guoqing Li $^{1}{ }^{*}$ and Chuanzhao Tian ${ }^{1}$ \\ 1 Institute of Remote Sensing and Digital Earth, Chinese Academy of Sciences, Beijing 100094, China; \\ zhanghy01@radi.ac.cn (H.Z.); huangmr@radi.ac.cn (M.H.); tiancz@radi.ac.cn (C.T.) \\ 2 The National Science Library, Chinese Academy of Sciences, Beijing 100090, China; \\ qingxl@mail.las.ac.cn \\ * Correspondence: ligq@radi.ac.cn; Tel.: +86-156-0105-0120
}

Received: 30 August 2017; Accepted: 26 October 2017; Published: 1 November 2017

\begin{abstract}
Bibliometric analysis based on the Science Citation Index Expanded published by Thomson Scientific was carried out to identify the research status and future trends of remote sensing (RS) during 2010-2015. The analysis revealed the institutional, national, spatio-temporal, and categorical patterns in remote sensing research both from the WP (whole publications) viewpoint and the HCP (highly-cited publications) viewpoint. Statistical analysis results showed that remote sensing research almost doubled during 2010-2015. Environmental sciences comprised the most attractive subject category among remote sensing research. The International Journal of Remote Sensing was the most productive journal, and Remote Sensing of Environment published the most HCP among the 31 distributed journals. The productive ranking of countries was led by the U.S. both from the WP viewpoint and the HCP viewpoint, and CAS (Chinese Academy of Sciences) was the most productive institute both from the WP viewpoint and the HCP viewpoint with lower CPP (average number of citations per paper). Keyword analysis illustrated that model and algorithm research were the key points in RS during 2010-2015. RS data including Moderate-Resolution Imaging Spectroradiometer (MODIS), Landsat, synthetic aperture radar (SAR), and LiDAR (light detection and ranging) were the most frequently adopted, but the data usage of UAVs (unmanned aerial vehicles) and small satellites will be promoted in the future. With the development of data acquisition abilities, big data issues will become the challenges and hotspots of RS research, and new algorithms will continue to emerge.
\end{abstract}

Keywords: remote sensing; bibliometric analysis; WP viewpoint; $\mathrm{HCP}$ viewpoint; $\mathrm{CPP}$

\section{Introduction}

Remote sensing is the practice of deriving information about the Earth's land and water surfaces using images acquired from an overhead perspective, using electromagnetic radiation in one or more regions of the electromagnetic spectrum, reflected or emitted from the Earth's surface [1]. With the development of modern technology, a variety of satellites and new sensors were launched, and data acquisition abilities were significantly enhanced [2]. The technology of airborne and spaceborne remote sensing systems continues to advance. According to the Union of Concerned Scientists (UCS) Satellite Database (15 September 2017), 671 satellites were launched during 2010-2015. It is worth mentioning that small satellites have been widely promoted and applied due to their small size, light weight, good performance, low cost, flexible transmission, and other characteristics [3-5]. There were 257 small satellites launched during 2010-2015, accounting for more than $48 \%$ of the total. Besides, unmanned aerial vehicles (UAVs) have attracted a great deal of attention in remote sensing research, as the number of UAV systems used in remote sensing and mapping continued to soar during 2010-2015.

From the aspect of research practices, the application of remote sensing on data processing, data fusion, image classification, geometric correction, and data noise reduction continued to increase, 
and new techniques and approaches emerged during 2010-2015. For example, Chen et al. [6] from the U.S. proposed a new sparsity-based algorithm for the classification of hyperspectral imagery in 2011. Tarabalka et al. [7] presented a novel method for accurate spectral-spatial classification of hyperspectral images. Ferretti et al. [8] from Italy introduced a new algorithm (SqueeSAR) for processing interferometric data stacks, and some people have improved this algorithm and compared it with other algorithms. Kennedy et al. [9] introduced and tested a new approach called LandTrendr (Landsat-based detection of Trends in disturbance and recovery) to extract the spectral trajectories of land surface change from yearly Landsat time series stacks. Furthermore, the integrated application of remote sensing continues to strengthen [6], and it is playing an important role in agriculture, forests research, ocean observation, city modeling, disaster detection, ecological environment, and natural resources. Moreover, new applications continued to emerge during these years [1,2]. In the literature analysis of the 34th Asian Remote Sensing Conference, Huang [2] summarized the application areas of 970 articles, providing a great reference to analyze the global remote sensing research.

The term "bibliometrics" was first proposed by Pritchard [10], defined as "the application of mathematical and statistical methods to books and other media of communication". It is an effective tool for analyzing the research trends of various study fields [11-16]. Chiu and Ho [11] applied a bibliometric analytical technique for examining tsunami research literature. Liu et al. [17] extended the bibliometric analysis approaches to evaluate earthquake research performance. Zhuang et al. [18] adopted the "geographical impact factor" to analyse the geographical influence on authors in remote sensing research. Such bibliometric analysis has greatly contributed to the evaluation of global remote sensing research and provided a supplementary perspective in revealing research frontiers.

This paper aims to provide a statistical overview of remote sensing studies by bibliometric analysis, to reveal the underlying patterns in scientific outputs, geographical distribution, as well as the hot issues of remote sensing research during 2010-2015. By doing so, we provide a potential guide for future remote sensing research. In order to perform a comprehensive analysis of remote sensing, the results were obtained from two perspectives: whole publications (WP) and highly-cited publications (HCP) [19].

\section{Data Source and Methods}

Until recently, the Web of Science (WoS) was the leading source for the assessment of scientific output worldwide because of its multidisciplinary and international coverage [20,21]. It includes more than 10,000 journals and comprises four citation databases: Science Citation Index Expanded (1900-present), Social Sciences Citation Index (1900-present), Arts and Humanities Citation Index (1975-present), and Emerging Sources Citation Index (ESCI) (2015-present) [22]. An alternative to the Web of Science is the database Scopus (Elsevier), which launched in 2004, covering over 15,000 peer-reviewed journals. These two databases index a great number of journals within most disciplines, but the coverage varies, as indicated in Table 1. In contrast to the above two databases, Google Scholar is a license-free service. However, due to the information about the coverage, the quality of indexed data and the difficulties in performing subject field normalization, it is not regarded as an alternative to the commercial citation databases as a source for evaluating studies [23]. Despite the emergence of bibliometric databases in recent years, the Science Citation Index (SCI) is still the most used index for scientific output [12]. The bibliometric data source in our study was extracted from the online version of the Science Citation Index Expanded (SCIE) by setting the Web of science Category (WC) to "remote sensing". Only publication records within the period from January 2010-December 2015 were selected. The publications obtained were documented in different journals, and the impact factors used in this study were from the 2013 Journal Citation Reports (JCR). The data collection was conducted on 8 September 2016. 
Table 1. Coverage comparison of the main bibliometric databases.

\begin{tabular}{|c|c|c|c|}
\hline $\begin{array}{l}\text { Bibliometric } \\
\text { Databases }\end{array}$ & ISI Web of Science (Thomson Reuters) & Scopus (Elsevier) & Google Scholar (Google Inc.) \\
\hline $\begin{array}{l}\text { Indexing and } \\
\text { abstracting }\end{array}$ & Yes & Yes & No \\
\hline \multirow[t]{4}{*}{$\begin{array}{l}\text { Years covered: } \\
\text { journals }\end{array}$} & $\begin{array}{l}\text { Science Citation Index Expanded } \\
\text { (SCI-Expanded), 1900-present }\end{array}$ & $\begin{array}{l}\text { 1996-present and some } \\
\text { journals date back to } 1966\end{array}$ & 1996 \\
\hline & $\begin{array}{l}\text { Social Sciences Citation Index (SSCI), } \\
\text { 1900-present }\end{array}$ & & \\
\hline & $\begin{array}{l}\text { Arts and Humanities Citation Index } \\
\text { (A and HCI), 1975-present }\end{array}$ & & \\
\hline & $\begin{array}{l}\text { Emerging Sources Citation Index (ESCI), } \\
\text { 2015-present }\end{array}$ & & \\
\hline $\begin{array}{l}\text { Years covered: } \\
\text { citations }\end{array}$ & 1900-present & $\begin{array}{l}\text { 1970-present (until the } \\
\text { end of 2016) }\end{array}$ & Not revealed \\
\hline Fee-based & Yes & Yes & No \\
\hline Contents & Approximately 10,000 refereed journals & 15,000 refereed journals & $\begin{array}{l}\text { Journals and books and } \\
\text { preprints and reports and } \\
\text { material from digital archives }\end{array}$ \\
\hline
\end{tabular}

The analysis tools adopted in this study include the Thomson Data Analyzer (TDA) [24], Excel, and VOSViewer [19]. In order to reflect the citation times of the publications, the data sources used in our study were separated into two parts: WP and HCP. Please refer to Section 3.1 to see the detailed criteria for choosing HCP.

The WP and the HCP were used to describe global remote sensing research during 2010-2015 from two perspectives, and both of them were analyzed with respect to the following four aspects:

- Publication output and citation analysis

- Distribution of output in journals and subject categories identified by ISI

- Distribution publications by country and institution

- Temporal evolution of hot issues

The most frequently used indices in our analysis are CPP (average number of citations per paper), TC (total citation times) and NP (number of publications). All these indicators are calculated according to the above four aspects. Since the number of publications and citation times of each article can be obtained from the data sources, the TC is calculated as shown below.

$$
T C=\sum_{c t=c t_{\text {min }}}^{c t_{\max }} c t \times N P(t)
$$

where $c t$ is the citation times of each publication and $N P(t)$ is the number of publications that were cited $t$ times. The $c t$ is between $c t_{\min }$ and $c t_{\max }$; in our analysis, $c t_{\min }=0, c t_{\max }=333$, which means $c t \in[0,333]$.

CPP was calculated according to the analysis unit. In our study, annual CPP, CPP within each subject category, and CPP within each journal were calculated. Taking the annual CPP as an example, the CPP of 2000 can be calculated as shown below.

$$
C P P_{2000}=\frac{T C_{2000}}{N P_{2000}}=\frac{\sum_{c t_{\min }}^{c t_{\max }} c t_{2000} \times n p_{2000}(t)}{N P_{2000}}
$$

where $C P P_{2000}$ represents the CPP of $2000, T C_{2000}$ is the total citation times of articles published in 2000 and $N P_{2000}$ is the total number of publications in $2000 . n p_{2000}(t)$ represents the number of articles published in 2000 that were cited $t$ times.

The algorithm could also be adopted to calculate CPP within each subject category and journal. 
In the geographical distribution analysis, the contributions of different countries were estimated by the affiliation of at least one author with the publications. Collaboration type was determined by the addresses of the authors, where the term "single-country article" was assigned if the researchers" addresses were from the same country. The term "international collaborative article" was designated to those publications that were co-authored by researchers from multiple countries [17,25]. The number of publications, citation times, as well as CPP were all calculated.

\section{Results Analysis}

\subsection{Publication Outputs}

The scientific output of remote sensing between 2010 and 2015 is shown in Table 2. The number of publications (NP) dedicated to remote sensing increased from 2503 in 2010 to 4898 in 2015. The total citation times (TC) for the 21,872 papers were 97,703. The average number of CPP was therefore 4.47.

Table 2. Annual outputs of WP (whole publications) in global remote sensing research. CPP: average number of citations per paper; NP: number of publications; TC: total citation times.

\begin{tabular}{cccccccc}
\hline Publish Year & $\mathbf{2 0 1 0}$ & $\mathbf{2 0 1 1}$ & $\mathbf{2 0 1 2}$ & $\mathbf{2 0 1 3}$ & $\mathbf{2 0 1 4}$ & $\mathbf{2 0 1 5}$ & $\mathbf{2 0 1 0 - 2 0 1 5}$ \\
\hline NP & 2503 & 2932 & 3199 & 3628 & 4712 & 4898 & 21,872 \\
TC & 27,056 & 25,821 & 20,890 & 12,301 & 5043 & 6592 & 97,703 \\
CPP & 10.81 & 8.81 & 6.53 & 3.39 & 1.07 & 1.35 & 4.47 \\
\hline
\end{tabular}

It needs to be pointed out that the number of citations for a single paper is highly correlated with the length of time since its publication [11]. In our case, the CPP in 2010 was almost ten times the CPP in 2014. This is evident as shown in Figure 1, where we show the annual publications and citations. As the statistics illustrate, for the same publications that were not published in the same year, there still existed bias in the citation analysis. As the statistics showed, the TC of publications in 2010 reached up to 27,056. The CPP was over 10.81, almost ten times the CPP in 2015 and 2014. The citation times of the publications will increase with the accumulation of years. However, the citation times of the publications in 2015 (1.35) was higher than the publications in 2014 (1.07) (Table 2), which implies that the attraction of the publications will decline over five years.

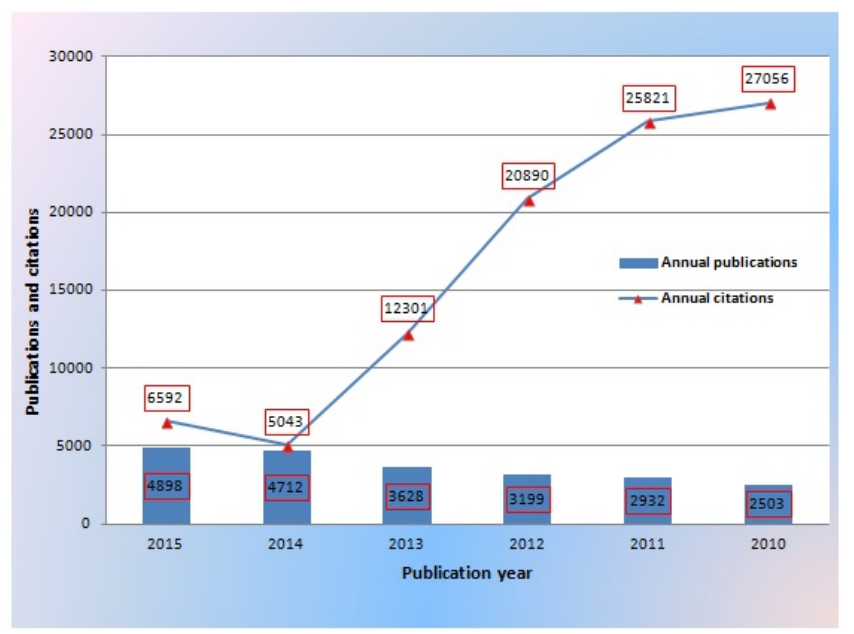

Figure 1. Annual publications and citations in remote sensing research during 2010-2015.

In order to diminish the impact of publication year on the articles, a criterion is needed to define the HCP. In this study, the annual CPP was used as a threshold. If the citation times of a particular 
paper were higher than the annual CPP, then it was considered as a highly-cited paper. The annual publications and citations can be seen in Figure 1. For example, the annual CPP in 2010 was 10.81, and the citation times of the article should be an integer, so the publications in 2010 that were cited more than ten times were defined as HCP. The same applied to the articles published in 2011, 2012, 2013, 2014, and 2015. The annual scientific output of HCP of 2010, 2011, 2012, 2013, 2014, and 2015 is shown in Table 3, totalling 6432 publications.

Table 3. Annual outputs of highly-cited publications (HCP) in global remote sensing research.

\begin{tabular}{cccccccc}
\hline Publish Year & $\mathbf{2 0 1 0}$ & $\mathbf{2 0 1 1}$ & $\mathbf{2 0 1 2}$ & $\mathbf{2 0 1 3}$ & $\mathbf{2 0 1 4}$ & $\mathbf{2 0 1 5}$ & $\mathbf{2 0 1 0 - 2 0 1 5}$ \\
\hline NP & 801 & 950 & 1052 & 1171 & 1093 & 1365 & 6432 \\
TC & 20,765 & 19,935 & 16,051 & 9478 & 3962 & 5468 & 70,191 \\
CPP & 25.9 & 21 & 15.3 & 8.1 & 3.6 & 4 & 11.8 \\
\hline
\end{tabular}

The most-cited paper in the bibliometric database was Friedl et al., (2010a), which described the methods and datasets used to create the land cover type product, which was accepted by Remote Sensing of Environment in 2010 and had been cited 333 times in total. There were 22 papers cited more than 100 times. Researchers based in the U.S. have published 12 papers, followed by France and Canada with five and three papers, respectively. Among the 22 most cited articles, there were eight papers on research techniques, approaches, and models; eight introduced new algorithms and improvements; four were overviews of remote sensing research; and two were about the application topic of remote sensing. It can be seen that algorithm- and technology-related articles took the highest proportion in remote sensing research.

\subsection{Subject Categories and Major Journals}

(1) WP viewpoint: Global remote sensing publications appeared in $32 \mathrm{SCI}$ indexed journals during 2010-2015. The statistics showed that there were six journals with over 1000 publications, among which Transactions on Geoscience and Remote Sensing ranked first with 2825 articles, followed by the International Journal of Remote Sensing (2639), Remote Sensing (2154), Remote Sensing of Environment (2085), IEEE Geoscience and Remote Sensing Letters (1924), IEEE Journal of selected Topics in applied Earth Observations and Remote Sensing (1541), and Journal of Applied Remote Sensing (1001).

Since the impact factor (IF) can reflect the global influence of the journals, we ranked the list according to the IF in descending order (Figure 2; the numbers in brackets represent the IF of the corresponding journals) along with the number of papers that the corresponding journals published. It can be seen from the figure that the IF of Photogrammetric Engineering and Remote Sensing Journal is 2.071; if IF $>=2.071$ were taken as high influence, the number of articles published in the high-influence journals would be 9696 , accounting for $44.3 \%$ of the total publications. 


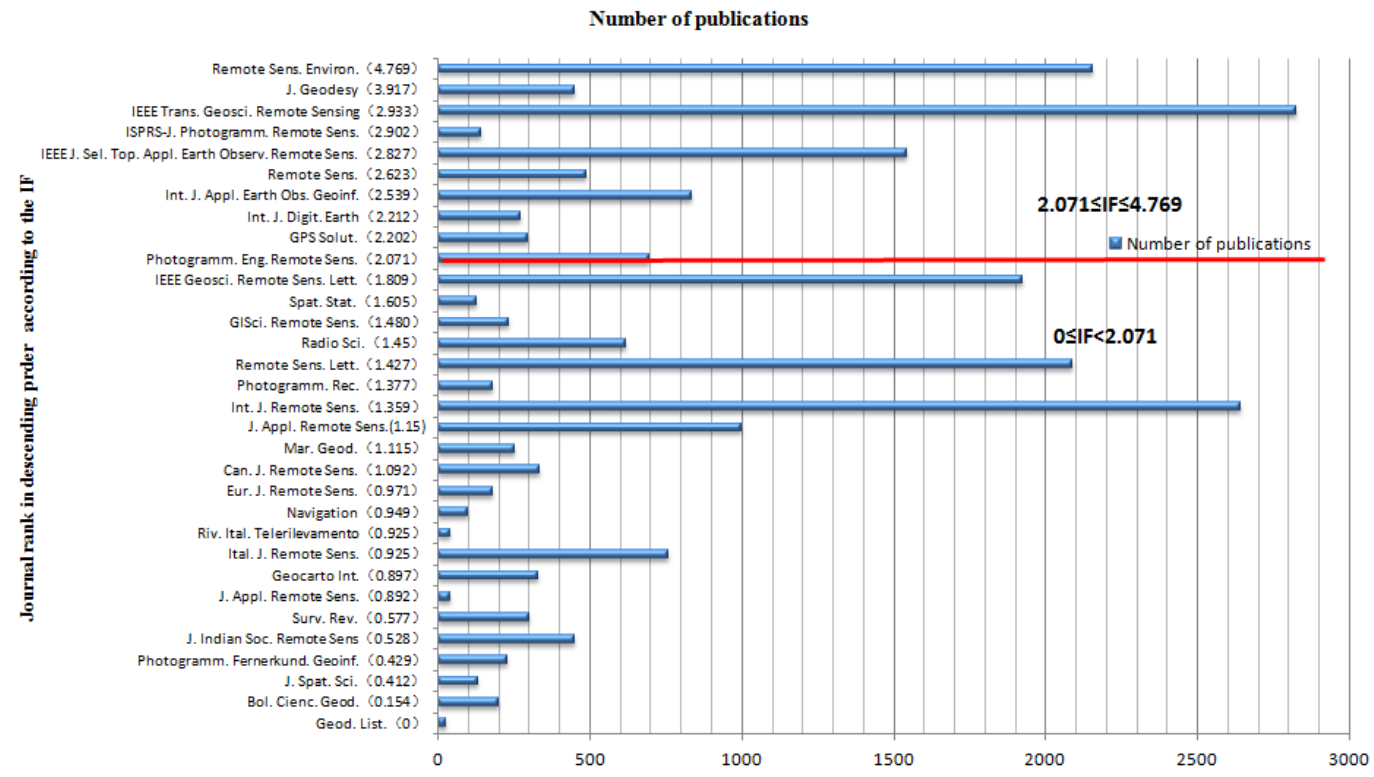

Figure 2. Remote sensing journals ranked in descending order according to the impact factor (IF).

Global remote sensing research spanned over 15 ISI-identified subject categories in our database. Besides remote sensing, the five other most common categories over 3000 publications were imaging science and photographic technology $(14,691)$, engineering, electrical and electronic (6270), geochemistry and geophysics (6265), geography and physical (3957), and environmental sciences (3864). CPP represents the average number of citations per publication within the respective field, and it can reflect the influence of the specific study field. The high IF of Remote Sensing of Environment has extended to the subject categories. As shown in Figure 3 (the number in the brackets represents the CPP of the corresponding category), the $\mathrm{CPP}$ of the environmental sciences category was the highest among all the subject categories, followed by engineering, electrical and electronic, geochemistry and geophysics, and imaging science and photographic; the CPP in these categories surpassed five.

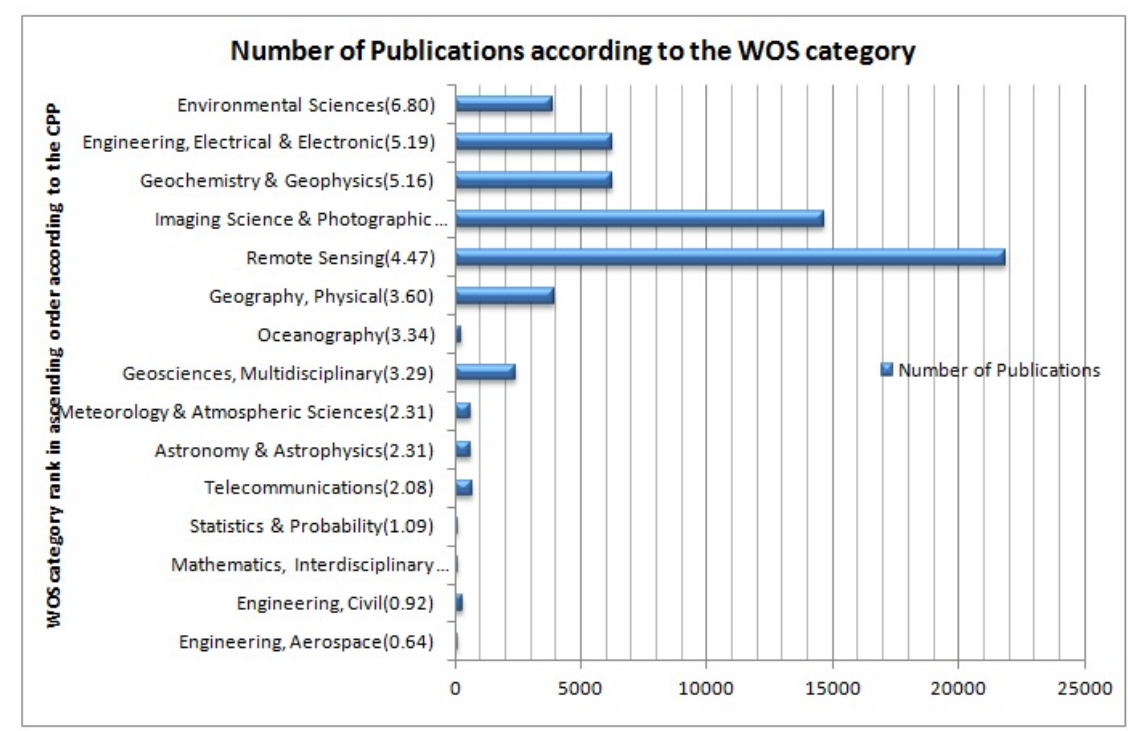

Figure 3. Number of publications within each Web of Science (WoS) category ranked in ascending order according to the CPP. 
(2) HCP viewpoint: From the viewpoint of HCP, there were nine journals that published over $100 \mathrm{HCP}$ in remote sensing research, led by Remote Sensing of Environment (1368) and IEEE Trans. Geosci. Remote Sensing (1297), which published over 1000 HCP, followed by Remote Sensing (684), the International Journal of Remote Sensing (450), IEEE Journal of Selected Topics in applied Earth Observations and Remote Sensing (442), International Journal of Applied Earth Observation and Geoinformation (376), ISPRS Journal of Photogrammetry and Remote Sensing (339), and Journal of Geodesy (156). The annual publications of HCP in the top nine journals are shown in Figure 4.

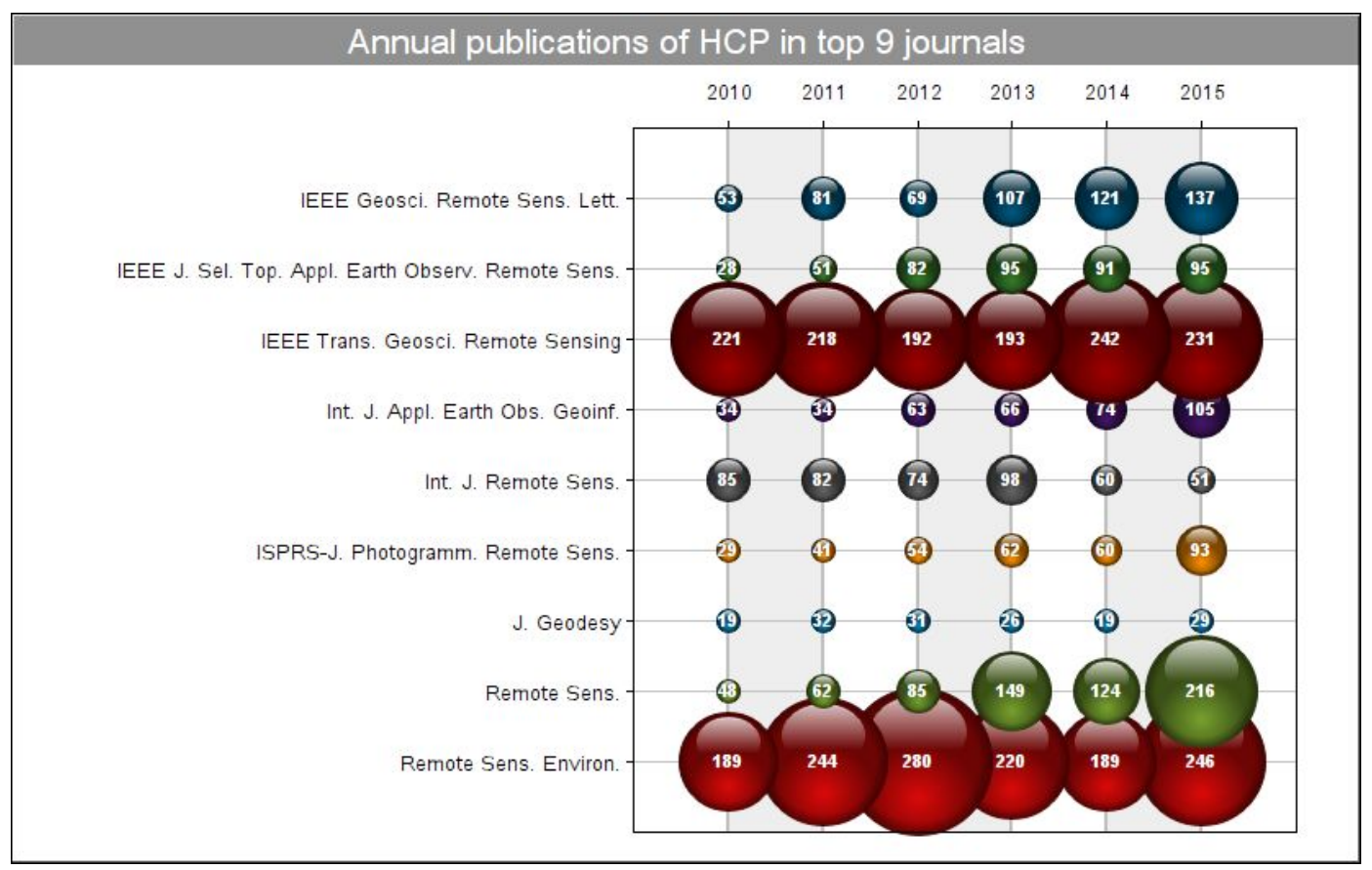

Figure 4. Annual publications of HCP in the top nine journals.

In order to make comparisons between the top journals of $\mathrm{HCP}$, the TC, NP, and CPP of each journal were calculated (Table 4). It was obvious that Remote Sensing of Environment was the most productive journal with the highest CPP (16.64). The CPP of the Journal of Geodesy was the second highest (14.28), followed by IEEE Trans. Geosci. Remote Sensing (13.36).

Table 4. Top nine journals of HCP in global remote sensing research. R: Rank.

\begin{tabular}{cccc}
\hline Journals & TC & NP & CPP (R) \\
\hline Remote Sens. Environ. & 22,764 & 1368 & $16.64(1)$ \\
IEEE Trans. Geosci. Remote Sensing & 17,327 & 1297 & $13.36(3)$ \\
Remote Sens. & 5556 & 684 & $8.12(9)$ \\
IEEE Geosci. Remote Sens. Lett. & 4809 & 568 & $8.47(8)$ \\
Int. J. Remote Sens. & 4643 & 450 & $10.32(5)$ \\
IEEE J. Sel. Top. Appl. Earth Observ. Remote Sens. & 4185 & 442 & $9.47(6)$ \\
Int. J. Appl. Earth Obs. Geoinf. & 3440 & 376 & $9.15(7)$ \\
ISPRS-J. Photogramm. Remote Sens. & 3883 & 339 & $11.45(4)$ \\
J. Geodesy & 2227 & 156 & $14.28(2)$ \\
\hline
\end{tabular}

From the HCP viewpoint, the most common categories besides remote sensing were imaging science and photographic technology with 4765 publications; engineering, electrical, and electronic with 2307 publications; geochemistry and geophysics with 2133 publications; environmental sciences with 1474 publications; and geography and physical with 1053 publications. In order to make a comparison between the WP viewpoint and the HCP viewpoint, we also calculated the CPP within 
each subject category of HCP. The CPP within-subject categories ranged from 6.5-15.9, among which environmental sciences ranked first (15.92), followed by oceanography (13.76). The statistics of the top WoS categories are shown in Table 5. The CPP of each category can reflect the influence of the specific research area. The high impact factor of Remote Sensing of Environment has extended to the subject categories, as shown in the table statistics.

Table 5. The WoS categories of HCP in global remote sensing research.

\begin{tabular}{cccc}
\hline WoS Categories & TC & NP & CPP (R) \\
\hline Remote Sensing & 75,659 & 6432 & $11.76(5)$ \\
Imaging Science and Photographic Technology & 60,488 & 4765 & $12.69(3)$ \\
Engineering and Electrical and Electronic & 26,321 & 2307 & $11.41(6)$ \\
Geochemistry and Geophysics & 25,530 & 2133 & $11.97(4)$ \\
Environmental Sciences & 23,464 & 1474 & $15.92(1)$ \\
Geography and Physical & 10,823 & 1053 & $10.28(8)$ \\
Geosciences and Multidisciplinary & 5761 & 517 & $11.14(7)$ \\
Telecommunications & 602 & 72 & $8.36(13)$ \\
Astronomy and Astrophysics & 589 & 70 & $8.41(11)$ \\
Meteorology and Atmospheric Sciences & 589 & 70 & $8.41(12)$ \\
Oceanography & 578 & 42 & $13.76(2)$ \\
Mathematics and Interdisciplinary Applications & 93 & 11 & $8.45(9)$ \\
Statistics and Probability & 93 & 11 & $8.45(10)$ \\
Engineering and Civil & 44 & 10 & $4.40(15)$ \\
Engineering and Aerospace & 13 & 2 & $6.50(14)$ \\
\hline
\end{tabular}

\subsection{Geographic and Institutional Distribution}

(1) WP viewpoint: We generated the data on the geographic and institutional distributions of publications based on the affiliation information of the authors. There were 182 countries/territories that participated in remote sensing research.

The 30 most productive countries/territories are summarized in Table 6, in terms of NP and TC for SCA (single-country articles) and ICA (international collaboration articles), respectively. Out of these 30 countries, 17 were from Europe, 5 were from Asia, 3 were from the Middle East, 2 were from North America, and 3 others were from South America and Oceania and Africa, respectively. It was obvious that the most productive countries were concentrated in North America, Europe, and East Asia. The productivity ranking of international-collaborated publications was led by the U.S., which was responsible for the most ICA (3279). However, China was the most productive country with the most single-country articles (3356). From the statistics, the highest CPP of the SCA occurred in Austria (10.35), followed by Denmark (9.07), Finland (8.12), Norway (7.75), and the Netherlands (7.31). Furthermore, it can be seen that the highest CPP of the ICA occurred in Portugal (10.32), followed by Austria (8.2), Denmark (7.29), Spain (7.19), and Switzerland (7.16). It showed that the CPP of articles in European countries was higher than other continents, and the CPP of the ICA and SCA in Asia and Middle Eastern countries was the lowest compared with other countries. This illustrated that remote sensing (RS) researchers of developing countries should strengthen the cooperation with researchers from developed countries (especially European countries). 
Table 6. The 30 most productive countries/territories in remote sensing research during 2010-2015. $\mathrm{CP}$ : international collaboration publication; SP: single-country publication.

\begin{tabular}{|c|c|c|c|c|c|c|c|c|c|}
\hline \multirow{2}{*}{ Country } & \multirow{2}{*}{ TP } & \multicolumn{4}{|c|}{ Single-Country } & \multicolumn{4}{|c|}{ International Collaboration } \\
\hline & & SP & TC & TC/SP & $\mathrm{SP} \%$ & $\mathrm{CP}$ & TC & $\mathrm{TC} / \mathrm{CP}$ & $\mathrm{CP} \%$ \\
\hline U.S. & 6062 & 2783 & 18,299 & 6.58 & 45.91 & 3279 & 17,182 & 5.24 & 54.09 \\
\hline China & 5447 & 3356 & 8788 & 2.62 & 61.61 & 2091 & 8901 & 4.26 & 38.39 \\
\hline Germany & 1875 & 692 & 4483 & 6.48 & 36.91 & 1183 & 6673 & 5.64 & 63.09 \\
\hline Italy & 1583 & 638 & 3710 & 5.82 & 40.30 & 945 & 5660 & 5.99 & 59.70 \\
\hline Canada & 1323 & 497 & 2436 & 4.90 & 37.57 & 826 & 4138 & 5.01 & 62.43 \\
\hline France & 1291 & 349 & 2366 & 6.78 & 27.03 & 942 & 6541 & 6.94 & 72.97 \\
\hline India & 1132 & 752 & 1466 & 1.95 & 66.43 & 380 & 1133 & 2.98 & 33.57 \\
\hline U.K. & 1054 & 361 & 1677 & 4.65 & 34.25 & 693 & 4223 & 6.09 & 65.75 \\
\hline Spain & 1019 & 380 & 1949 & 5.13 & 37.29 & 639 & 4597 & 7.19 & 62.71 \\
\hline Australia & 908 & 311 & 1538 & 4.95 & 34.25 & 597 & 3208 & 5.37 & 65.75 \\
\hline The Netherlands & 823 & 134 & 979 & 7.31 & 16.28 & 689 & 4539 & 6.59 & 83.72 \\
\hline Japan & 672 & 244 & 1084 & 4.44 & 36.31 & 428 & 1938 & 4.53 & 63.69 \\
\hline Brazil & 497 & 276 & 521 & 1.89 & 55.53 & 221 & 1185 & 5.36 & 44.47 \\
\hline Switzerland & 402 & 75 & 502 & 6.69 & 18.66 & 327 & 2342 & 7.16 & 81.34 \\
\hline Finland & 342 & 156 & 1267 & 8.12 & 45.61 & 186 & 890 & 4.78 & 54.39 \\
\hline Belgium & 341 & 99 & 533 & 5.38 & 29.03 & 242 & 1569 & 6.48 & 70.97 \\
\hline South Korea & 326 & 115 & 356 & 3.10 & 35.28 & 211 & 730 & 3.46 & 64.72 \\
\hline Iran & 312 & 130 & 396 & 3.05 & 41.67 & 182 & 415 & 2.28 & 58.33 \\
\hline Austria & 307 & 60 & 621 & 10.35 & 19.54 & 247 & 2026 & 8.2 & 80.46 \\
\hline Turkey & 268 & 148 & 362 & 2.45 & 55.22 & 120 & 608 & 5.07 & 44.78 \\
\hline Sweden & 238 & 86 & 459 & 5.34 & 36.13 & 152 & 793 & 5.22 & 63.87 \\
\hline Norway & 234 & 80 & 620 & 7.75 & 34.19 & 154 & 994 & 6.45 & 65.81 \\
\hline Greece & 223 & 88 & 322 & 3.66 & 39.46 & 135 & 499 & 3.7 & 60.54 \\
\hline Russia & 190 & 61 & 126 & 2.07 & 32.11 & 129 & 544 & 4.22 & 67.89 \\
\hline Portugal & 188 & 37 & 212 & 5.73 & 19.68 & 151 & 1558 & 10.32 & 80.32 \\
\hline South Africa & 179 & 62 & 392 & 6.32 & 34.64 & 117 & 731 & 6.25 & 65.36 \\
\hline Denmark & 163 & 30 & 272 & 9.07 & 18.40 & 133 & 969 & 7.29 & 81.60 \\
\hline Poland & 127 & 59 & 181 & 3.07 & 46.46 & 68 & 251 & 3.69 & 53.54 \\
\hline Israel & 122 & 60 & 182 & 3.03 & 49.18 & 62 & 214 & 3.45 & 50.82 \\
\hline Malaysia & 118 & 40 & 93 & 2.33 & 33.90 & 78 & 262 & 3.36 & 66.10 \\
\hline
\end{tabular}

The growing scientific productivity in remote sensing was commonly ascribed to the increasing amount of SCI and Social Sciences Citation Index (SSCI)-indexed publications [26], but the satellite development may also be another important element pushing it. As stated in the Introduction, there were 671 satellites launched during 2010-2015. The U.S. has owned and operated the most satellites (201), which was consistent with the fact that the U.S. produced the most articles on remote sensing. China ranked second (137) in the number of satellites, followed by Russia (84). The number of satellites and small satellites launched by each country during 2010-2015 is shown in Table 7. As an important remote sensing platform, satellites provided a large number of basic data for remote sensing research. Zhuang et al. [18] analyzed the relationship between remote sensing research and satellite development, and the observation revealed that satellite development is one of the main driving forces of remote sensing research. In our study, it could also be seen that most of the developed countries who owned and operated more satellites published more remote sensing articles. This verified the conclusion that satellite development can greatly promote scientific publication. 
Table 7. Number of satellites and smallsats launched during 2010-2015 by each country.

\begin{tabular}{|c|c|c|}
\hline Country of Operator/Owner & Number of All Launched Satellites & Number of Small Satellites \\
\hline USA & 201 & 84 \\
\hline China & 137 & 37 \\
\hline Russia & 84 & 33 \\
\hline Japan & 27 & 15 \\
\hline United Kingdom & 25 & 7 \\
\hline Multinational & 24 & 2 \\
\hline ESA & 19 & 4 \\
\hline India & 19 & 4 \\
\hline Canada & 16 & 12 \\
\hline Singapore & 9 & 9 \\
\hline Germany & 8 & 6 \\
\hline South Korea & 7 & 2 \\
\hline Luxembourg & 6 & 0 \\
\hline Spain & 6 & 3 \\
\hline Argentina & 5 & 3 \\
\hline France & 5 & 4 \\
\hline Israel & 4 & 3 \\
\hline Kazakhstan & 4 & 1 \\
\hline Turkey & 4 & 2 \\
\hline France/Italy & 3 & 0 \\
\hline Mexico & 3 & 0 \\
\hline Nigeria & 3 & 2 \\
\hline Norway & 3 & 2 \\
\hline United Arab Emirates & 3 & 1 \\
\hline Australia & 2 & 0 \\
\hline Belgium & 2 & 2 \\
\hline Brazil & 2 & 0 \\
\hline France/Belgium/Sweden & 2 & 0 \\
\hline India/France & 2 & 1 \\
\hline Russia/USA & 2 & 2 \\
\hline USA/Argentina & 2 & 2 \\
\hline USA/Japan & 2 & 0 \\
\hline Vietnam & 2 & 1 \\
\hline Algeria & $\overline{1}$ & 1 \\
\hline Austria & 1 & 1 \\
\hline Azerbaijan & 1 & 0 \\
\hline Belarus & 1 & 1 \\
\hline Bolivia & 1 & 0 \\
\hline Chile & 1 & 1 \\
\hline China/Brazil & 1 & 0 \\
\hline Denmark & 1 & 1 \\
\hline Egypt & 1 & 0 \\
\hline India9Canada & 1 & 0 \\
\hline Indonesia & 1 & 1 \\
\hline Iraq & 1 & 1 \\
\hline Italy & 1 & 0 \\
\hline Laos & 1 & 0 \\
\hline Malaysia & 1 & 0 \\
\hline Netherlands & 1 & 1 \\
\hline Pakistan & 1 & 0 \\
\hline Peru & 1 & 1 \\
\hline Saudi Arabia & 1 & 1 \\
\hline Singapore/China Taiwan & 1 & 0 \\
\hline South Africa & 1 & 0 \\
\hline Switzerland & 1 & 1 \\
\hline Thailand & 1 & 0 \\
\hline Turkmenistan/Monaco & 1 & 0 \\
\hline Ukraine & 1 & 1 \\
\hline United Kingdom/ESA & 1 & 0 \\
\hline Uruguay & 1 & 1 \\
\hline Venezuela & 1 & 0 \\
\hline
\end{tabular}

Among the 7206 research institutes/organizations that participated in remote sensing research, the Chinese Academy of Sciences (CAS) led the institutional productivity with 1879 articles, followed by Wuhan University (WHU) with 766 articles, the National Aeronautics and Space Administration (NASA) with 706 articles, the University of Maryland (UM) with 503, Beijing Normal University (BNU) with 495, German AerospCtrDLR with 418, Caltech with 364, and NOAA 306. Out of the 30 most prolific institutes/organizations with over 100 publications, 12 were in the U.S., 8 were in China, 3 were from Germany, 2 were from the Netherlands and Canada, respectively, and 3 other institutes were located in Spain, India, and Finland, respectively. 
CPP was calculated to represent the citation score of each research institute. The results showed that the CPP of the top 10 institutes was led by NASA with 8.47, followed by the German Aerospace Center (DLR) with 7.82, and Caltech with 7.25. Although CAS was the most productive institute, the CPP was 3.53, ranking nine in the top 10 institutes. Table 8 shows the NP, TC, and CPP (rank) of the top ten productive institutes.

Table 8. Output of the top ten institutes in remote sensing research from the WP viewpoint. CAS: Chinese Academy of Sciences; DLR: German Aerospace Center; NASA: National Aeronautics and Space Administration.

\begin{tabular}{cccc}
\hline Institute & TC & NP & CPP (R) \\
\hline CAS & 6625 & 1879 & $3.53(9)$ \\
Wuhan University & 2744 & 766 & $3.58(8)$ \\
NASA & 5981 & 706 & $8.47(1)$ \\
UMD & 3498 & 503 & $6.95(4)$ \\
Beijing Normal University & 2445 & 495 & $4.94(7)$ \\
DLR & 3268 & 418 & $7.82(2)$ \\
Caltech & 2640 & 364 & $7.25(3)$ \\
NOAA & 1721 & 306 & $5.62(6)$ \\
Xidian University & 786 & 276 & $2.85(10)$ \\
University of Twente & 1573 & 273 & $5.76(5)$ \\
\hline
\end{tabular}

(2) HCP viewpoint: From the viewpoint of $\mathrm{HCP}$, there were 16 countries that published more than $100 \mathrm{HCP}$ in remote sensing research. The U.S. led the most influential countries with $2148 \mathrm{HCP}$, followed by China with 1485, then Germany with 716, Italy with 617, France with 532, Canada with 405, and Spain with 398. From the geographical distribution of HCP, we can see that the HCP in remote sensing research were concentrated mostly in European countries, North American countries, and East Asia.

The high influence of the U.S. and China in remote sensing research has extended to the institutional level. There were nine institutes that published over $100 \mathrm{HCP}$, led by CAS with 517 HCP, followed by NASA with 333, UMD with 237, WHU with 236, DLR with 189, BNU with 184, Caltech with 154, NOAA with 115, and University of Twente with 111. The NP, TC, and CPP of the top nine institutes that published over $100 \mathrm{HCP}$ are demonstrated in Table 9. The statistics showed that NASA and Caltech ranked first in the high citation times of HCP in remote sensing research, followed by GAC and UM. Chinese institutes were the most productive institutes, but having low CPP, which indicated that international cooperation needs to be strengthened so as to attract more world attention.

Table 9. Output of the top nine institutes in remote sensing research from the HCP viewpoint.

\begin{tabular}{lccc}
\hline Institute & TC & NP & CPP \\
\hline CAS & 4890 & 517 & 9.46 \\
NASA & 5258 & 333 & 15.79 \\
UMD & 3083 & 237 & 13.01 \\
Wuhan University & 2162 & 236 & 9.16 \\
DLR & 2848 & 189 & 15.07 \\
Beijing Normal University & 1988 & 184 & 10.8 \\
Caltech & 2266 & 154 & 14.71 \\
NOAA & 1427 & 115 & 12.41 \\
University of Twente & 1356 & 111 & 12.22 \\
\hline
\end{tabular}

\subsection{Temporal Evolution of Keywords' Frequencies}

The author keywords were provided by article authors as a part of the articles, and the additional keywords were produced by ISI based on each article's citations and references. Both author keywords and additional keywords were adopted to demonstrate the research trends in our study. 
(1) WP viewpoint: Author keywords covered 73\%, and the additional keywords covered $87 \%$ of the total of 16,974 publications in remote sensing research during 2010-2015. After the author keywords and the additional keywords were merged together, 47,616 keywords were obtained. However, the data included inconsistencies, and these inconsistencies ranged from spelling differences (intentional or accidental) to synonyms (different terms for the same concepts; e.g., happy and glad). Since accurate analysis relies on minimizing such inconsistencies, the keywords were firstly preprocessed by data cleaning approaches. The preprocessing technique included a number filter, a punctuation eraser, a stop word filter, an English stemmer, and a self-defined regex filter. Machine-assisted recognition and rule-based recognition were adopted to merge the synonyms and to reduce the keyword list dimension in our study.

After data cleaning, 42,121 keywords were obtained. The keywords appeared in 12,431 publications, and 9653 (35\%) of these keywords appeared in one paper, with 10,277 (37\%) keywords appearing in more than 10 papers. In order to find the most prevalent technology terms, frequently appearing meaningful keywords were selected manually as the technology terms. Then, a word cloud was generated based on the document frequency (DF) of the keywords. Figure 5 displays such a visual representation, where a higher frequency results in a larger font size. Looking beyond expected terms such as climate change, boreal forest, time series, and satellite data, we could see the trends of published works during 2010-2015. In addition, MODIS (Moderate-Resolution Imaging Spectroradiometer), Landsat, Advanced Very High Resolution Radiometer (AVHRR), and LiDAR (light detection and ranging) were the prevailing sensors, while climate change and forest research showed a significant presence.

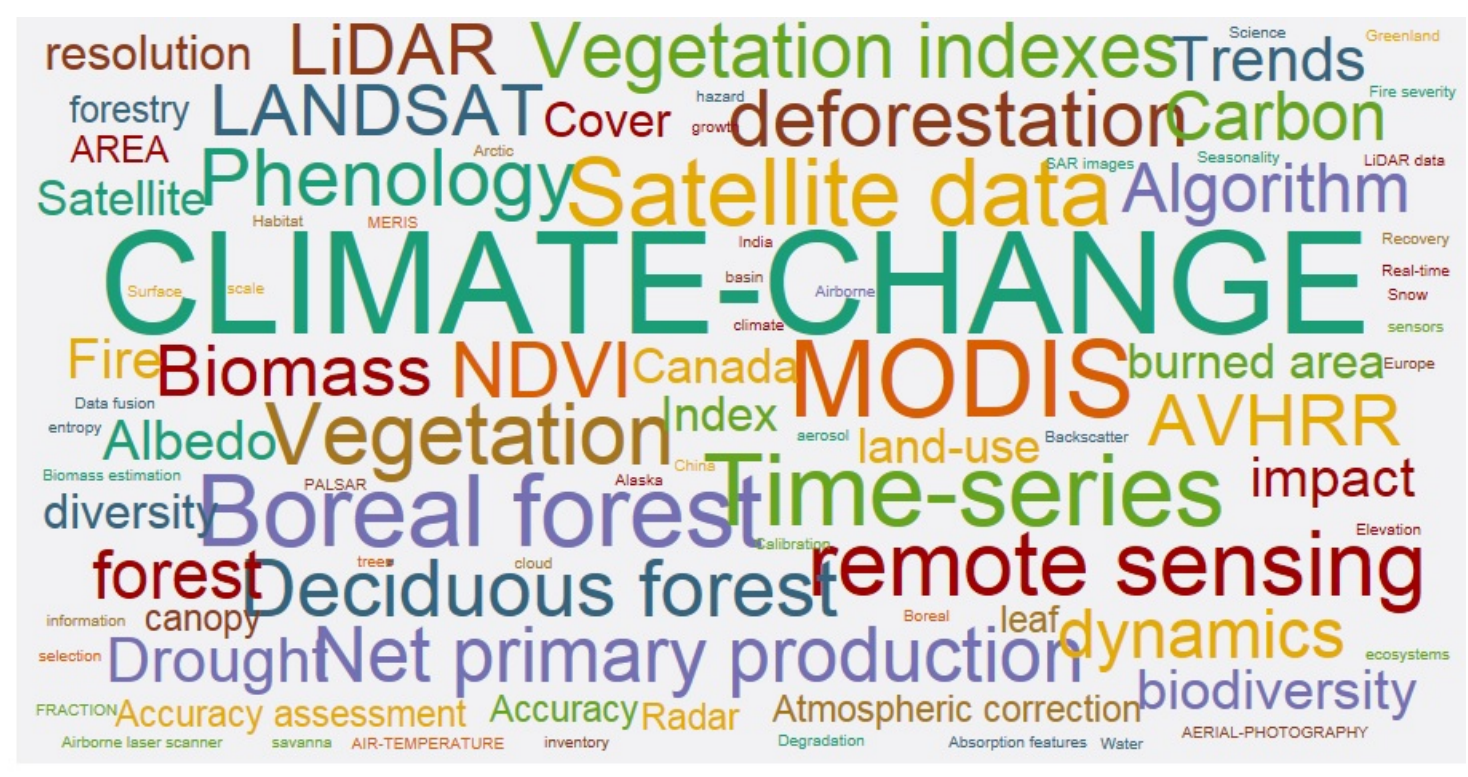

Figure 5. Visualization of the word cloud on the selected technology keywords.

In order to trace the temporal trend of the main topic in remote sensing research, the whole study period was separated into six annual intervals, and the top 30 keywords were detected. The detailed change detection of the 30 most frequently-used keywords within each of the one-year intervals is presented in Table 10. During this period, 30 or $0.11 \%$ of the keywords appeared in 5312 articles, thus being responsible for $42.7 \%$ of the total keyword occurrences. The relevant indicators, including the count of paper records, rank, change in rank, and total citations of papers, were chosen in the analysis. 
Table 10. Temporal evolution of the top 30 keywords in remote sensing research (ranking according to CPP in descending order). CC: change in count of paper records; CPP: citation times of per paper; LiDAR: light detection and ranging; MODIS: Moderate-Resolution Imaging Spectroradiometer; TC: total citations of papers that have the corresponding keywords ; TP: total publications that have the corresponding keywords.

\begin{tabular}{|c|c|c|c|c|c|c|c|c|c|c|c|c|c|c|c|c|}
\hline Author Keywords & $\begin{array}{c}2015 \\
\text { Cnt }\end{array}$ & $\mathbf{R}$ & $\begin{array}{c}2014 \\
\text { Cnt }\end{array}$ & $\mathbf{R}$ & $\begin{array}{r}2013 \\
\text { Cnt }\end{array}$ & $\mathbf{R}$ & $\begin{array}{r}2012 \\
\text { Cnt }\end{array}$ & $\mathbf{R}$ & $\begin{array}{c}2011 \\
\text { Cnt }\end{array}$ & $\mathbf{R}$ & $\begin{array}{r}2010 \\
\text { Cnt }\end{array}$ & $\mathbf{R}$ & $\mathrm{CC}$ & RC & TC & CPP \\
\hline Remote sensing data & 189 & 11 & 160 & 16 & 130 & 12 & 127 & 11 & 108 & 10 & 66 & 15 & 123 & $4 \uparrow$ & 6020 & 7.72 \\
\hline Landsat & 128 & 28 & 132 & 25 & 88 & 28 & 89 & 22 & 45 & 31 & 39 & 31 & 89 & $3 \uparrow$ & 3757 & 7.21 \\
\hline MODIS & 280 & 6 & 318 & 6 & 240 & 6 & 175 & 6 & 168 & 7 & 130 & 6 & 150 & 0 & 9165 & 6.99 \\
\hline LiDAR & 161 & 15 & 153 & 19 & 117 & 16 & 91 & 20 & 100 & 13 & 71 & 12 & 90 & $3 \downarrow$ & 4632 & 6.68 \\
\hline Leaf Area Index & 118 & 29 & 120 & 27 & 99 & 24 & 88 & 23 & 71 & 22 & 51 & 23 & 67 & $6 \downarrow$ & 3651 & 6.67 \\
\hline Satellite data & 108 & 30 & 104 & 30 & 99 & 25 & 79 & 26 & 68 & 26 & 43 & 28 & 65 & $2 \downarrow$ & 3323 & 6.63 \\
\hline Time series & 206 & 10 & 186 & 10 & 111 & 17 & 76 & 28 & 55 & 30 & 42 & 29 & 164 & $19 \uparrow$ & 4311 & 6.38 \\
\hline Vegetation & 240 & 8 & 252 & 7 & 210 & 7 & 161 & 8 & 179 & 5 & 115 & 7 & 125 & $1 \downarrow$ & 7294 & 6.3 \\
\hline Vegetation indexes & 142 & 21 & 132 & 23 & 108 & 21 & 98 & 17 & 74 & 21 & 61 & 21 & 81 & 0 & 3864 & 6.28 \\
\hline Validation & 222 & 9 & 227 & 9 & 156 & 9 & 142 & 9 & 117 & 9 & 78 & 10 & 144 & $1 \uparrow$ & 5696 & 6.05 \\
\hline Products & 133 & 26 & 146 & 20 & 82 & 29 & 71 & 29 & 64 & 28 & 46 & 25 & 87 & $1 \downarrow$ & 3194 & 5.89 \\
\hline Remote sensing & 362 & 5 & 424 & 4 & 287 & 4 & 253 & 3 & 212 & 3 & 224 & 2 & 138 & $3 \downarrow$ & 9994 & 5.67 \\
\hline Calibration & 130 & 27 & 109 & 28 & 104 & 23 & 98 & 18 & 69 & 24 & 74 & 11 & 56 & $16 \downarrow$ & 3281 & 5.62 \\
\hline Accuracy & 142 & 20 & 179 & 13 & 111 & 19 & 122 & 13 & 93 & 15 & 70 & 13 & 72 & $7 \downarrow$ & 3966 & 5.53 \\
\hline Retrieval & 183 & 12 & 172 & 14 & 139 & 11 & 131 & 10 & 101 & 12 & 98 & 8 & 85 & $4 \downarrow$ & 4536 & 5.5 \\
\hline Resolution & 139 & 24 & 105 & 29 & 72 & 30 & 60 & 31 & 62 & 29 & 64 & 18 & 75 & $6 \downarrow$ & 2747 & 5.47 \\
\hline Segmentation & 150 & 17 & 181 & 12 & 111 & 18 & 84 & 25 & 67 & 27 & 44 & 27 & 106 & $10 \uparrow$ & 3418 & 5.37 \\
\hline Classification & 511 & 2 & 512 & 1 & 337 & 2 & 310 & 2 & 217 & 2 & 183 & 3 & 328 & $1 \uparrow$ & 11,041 & 5.33 \\
\hline Radar & 107 & 31 & 122 & 26 & 96 & 27 & 78 & 27 & 70 & 23 & 69 & 14 & 38 & $17 \downarrow$ & 2877 & 5.31 \\
\hline Forest & 139 & 23 & 145 & 21 & 119 & 15 & 94 & 19 & 90 & 16 & 57 & 22 & 82 & $1 \downarrow$ & 3368 & 5.23 \\
\hline Synthetic aperture radar (SAR) & 368 & 4 & 368 & 5 & 257 & 5 & 231 & 5 & 195 & 4 & 145 & 5 & 223 & $1 \uparrow$ & 8113 & 5.19 \\
\hline Algorithm & 477 & 3 & 477 & 3 & 314 & 3 & 239 & 4 & 175 & 6 & 159 & 4 & 318 & $1 \uparrow$ & 9227 & 5.01 \\
\hline Satellite & 147 & 19 & 157 & 17 & 119 & 14 & 101 & 16 & 89 & 17 & 63 & 20 & 84 & $1 \uparrow$ & 3362 & 4.97 \\
\hline Model & 523 & 1 & 511 & 2 & 355 & 1 & 344 & 1 & 290 & 1 & 233 & 1 & 290 & 0 & 11,150 & 4.94 \\
\hline Imagery & 252 & 7 & 245 & 8 & 197 & 8 & 163 & 7 & 141 & 8 & 88 & 9 & 164 & $2 \uparrow$ & 5299 & 4.88 \\
\hline Surface & 140 & 22 & 98 & 31 & 69 & 31 & 71 & 30 & 77 & 19 & 65 & 16 & 75 & $6 \downarrow$ & 2521 & 4.85 \\
\hline Reflectance & 149 & 18 & 170 & 15 & 125 & 13 & 127 & 12 & 88 & 18 & 64 & 17 & 85 & $1 \downarrow$ & 3293 & 4.55 \\
\hline Area & 171 & 14 & 181 & 11 & 109 & 20 & 107 & 14 & 75 & 20 & 50 & 24 & 121 & $10 \uparrow$ & 3147 & 4.54 \\
\hline Images & 171 & 13 & 156 & 18 & 152 & 10 & 105 & 15 & 108 & 11 & 63 & 19 & 108 & $6 \uparrow$ & 3232 & 4.28 \\
\hline Variability & 136 & 25 & 132 & 24 & 107 & 22 & 89 & 21 & 98 & 14 & 44 & 26 & 92 & $1 \uparrow$ & 2390 & 3.94 \\
\hline
\end{tabular}

The change showed the evolution of the hot issues. Among the most frequently-used keywords, "model" ranked first, followed by "classification', "algorithm", "SAR" (synthetic aperture radar), "remote sensing", and "MODIS" within the top six author keywords, and the occurrence frequency increased during the six-year period (Table 10). The occurrence of "model" increased from 233 in 2010 to 523 in 2015, and the rank was always first (except for 2014) during the six-year period. The document frequency (DF) of "algorithm" increased from 159 in 2010 to 477 in 2015, and the rank was promoted from fourth to third during the six-year period. As Table 10 shows, remote sensing data were attracting researchers' attention during these years, as the table shows that the DF increased in the six-year period and the rank improved from 15th to 11th. The usage of "time series" increased from 42 in 2010 to 206 in 2015, with the rank upgraded from 29th to 10th. Although "MODIS" had not appeared in the co-word network until the period of 2001-2005 [18], it emerged as the core theme during 2010-2015, as the table illustrates that "MODIS" always ranked in the top seven keywords, and the DF increased from 130 in 2010 to 280 in 2015. "Landsat" increased from 39 in 2010 to 128 in 2015, and the rank improved by 3 during 2010-2015. "LiDAR" increased from 71 in 2010 to 161 in 2015, but the rank dropped from 12th in 2010 to 15th in 2015. "SAR" was a major tool for the investigation of ocean, agricultural crop, and forest in the past few years [18]. The usage of "SAR" increased from 145 in 2010 to 368 in 2015, and the rank was promoted by one during the study period. The observation revealed that the usage of remote sensing data kept growing during 2010-2015, and "MODIS", "Landsat", "LiDAR", and "SAR" were the most frequently-used data types. From the temporal variation, it was also illustrated that the hot issues including "model", "algorithm", "classification" and "time series" were 
continually emerging in 2010-2015. Zhuang et al. [18] revealed that "calibration" was a core theme during 2005-2010; however, the rank of "calibration" declined from 11th to 27th during 2010-2015.

The top 30 keywords reflected the content of remote sensing research mainly focusing on the following three aspects: data-related, application-relevant, and algorithm-related topics. It should be noted that the three groups can have cross-folds, and not all the papers can be categorized into these groups. It simply reflected the most prevalent research issues in remote sensing research. In order to further analyze the hot issues in remote sensing research, we manually grouped the most frequent keywords into three categories.

We obtained the most frequently-used data-related satellites and sensors from the keywords, including MODIS, Landsat, AVHRR, ASTER, SPOT, IKONOS, PALSAR, UAV, RADARSAT, QuickBird, WorldView, Sentinel, FORMOSAT, GOES, Cartosat, and DMC. The annual number of papers on these technology terms is given in Table 11. It was obvious that MODIS and Landsat were the prevalent data sources among all the data types. From the temporal variation, we can see that the usage of MODIS and Landsat was enhanced annually. It needs to be stated that due to the advantage of all the possible forms and sizes, UAVs can fly a multitude of remote sensing instruments for many applications [27]. Low-altitude UAVs can achieve high resolution, which were used to carry light-weight instruments, and it has benefited many remote sensing applications. As the statistics showed, more than 100 articles used UAVs to perform remote sensing applications. For example, the management of agricultural and natural resources has been successfully done using UAVs [28], such as precision agriculture, forest structure, and tree classification $[29,30]$. Besides, rapid response imaging using UAVs has received much attention as well. Between 2006 and 2010, the National Aeronautics and Space Administration (NASA) and the U.S. Forest Service flew 14 unmanned airborne system (UAS) sensor missions, detecting over 57 fires in the western U.S. [31]. UAVs also have been used for disaster detection, such as rapidly responding to landslides and debris flow events [32,33]. The flexibility of UAVs also played an important role in road target tracking [34].

Table 11. Statistical analysis of the main satellites and sensors in remote sensing research.

\begin{tabular}{cccccccc}
\hline Satellites and Sensors & $\mathbf{2 0 1 5}$ & $\mathbf{2 0 1 4}$ & $\mathbf{2 0 1 3}$ & $\mathbf{2 0 1 2}$ & $\mathbf{2 0 1 1}$ & $\mathbf{2 0 1 0}$ & Total Records \\
\hline MODIS & 453 & 476 & 350 & 255 & 228 & 174 & 1936 \\
Landsat & 288 & 278 & 187 & 176 & 126 & 104 & 1159 \\
AVHRR & 73 & 121 & 104 & 82 & 98 & 56 & 534 \\
ASTER & 53 & 63 & 61 & 52 & 44 & 37 & 310 \\
SPOT & 28 & 47 & 41 & 36 & 41 & 29 & 222 \\
IKONOS & 33 & 34 & 31 & 28 & 27 & 26 & 179 \\
PALSAR & 36 & 46 & 27 & 29 & 15 & 14 & 167 \\
UAV & 33 & 32 & 21 & 17 & 9 & 3 & 115 \\
RADARSAT & 22 & 27 & 13 & 17 & 16 & 7 & 102 \\
QuickBird & 9 & 26 & 19 & 14 & 13 & 18 & 99 \\
WorldView & 33 & 28 & 16 & 18 & 1 & 1 & 97 \\
Sentinel & 27 & 15 & 11 & 17 & 3 & 0 & 73 \\
FORMOSAT & 8 & 1 & 3 & 7 & 4 & 11 & 34 \\
GOES & 4 & 5 & 12 & 2 & 2 & 3 & 28 \\
Cartosat & 2 & 5 & 8 & 4 & 2 & 1 & 22 \\
DMC & 1 & 3 & 2 & 1 & 0 & 1 & 8 \\
\hline
\end{tabular}

The application fields of remote sensing research were manually categorized into seven groups: forest research, land cover, agriculture, global change, grasslands, city, and fishery. The DF of each group is shown in Table 12. Since forest research occupied the largest amount in all applications, the sub-topics of forest research were further analyzed in our study. Annual paper records on each subtopic of forest research were counted (Figure 6). As the figure shows, forest study mainly focused on the subtopics of boreal forest, tropical forest, deforestation, rainforest, forest inventory, and forestry, and the paper records of each subtopic were over 100. It can be seen that the articles on each subtopic 
kept increasing over time. Using the same approach, the studies on agriculture crops were classified, and it was found that wheat, rice paddy, and maize were the main topics.

Table 12. Statistical analysis of prevalent applications in remote sensing research.

\begin{tabular}{cccccccc}
\hline Application Fields & $\mathbf{2 0 1 5}$ & $\mathbf{2 0 1 4}$ & $\mathbf{2 0 1 3}$ & $\mathbf{2 0 1 2}$ & $\mathbf{2 0 1 1}$ & $\mathbf{2 0 1 0}$ & Total Records \\
\hline Forest research & 470 & 519 & 415 & 360 & 300 & 215 & 2279 \\
Land cover and land use & 324 & 338 & 258 & 226 & 174 & 126 & 1446 \\
Agriculture & 219 & 226 & 140 & 102 & 97 & 83 & 867 \\
Climate change and global change & 140 & 108 & 82 & 52 & 49 & 31 & 462 \\
Grassland & 45 & 45 & 33 & 22 & 13 & 8 & 166 \\
City & 38 & 34 & 22 & 21 & 18 & 11 & 144 \\
Fishery & 3 & 4 & 3 & 8 & 3 & 4 & 25 \\
\hline
\end{tabular}

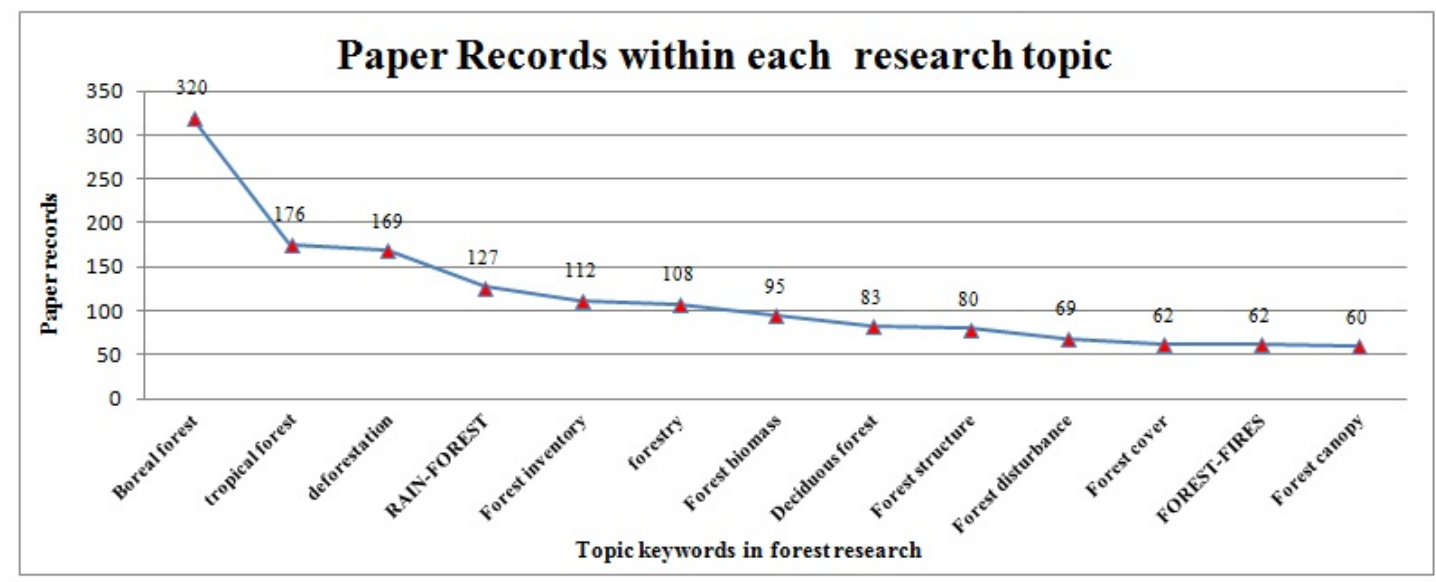

Figure 6. Paper records within each subtopic of forest research in remote sensing.

Remote sensing change detection and monitoring methods can be classified into seven groups, including direct comparison, classification, object-oriented method, model method, time series analysis, visual analysis, and hybrid methods [35]. According to our bibliometric analysis, most of the research was focused on classification approaches [7,36,37]. It was discovered that the four main algorithms used in remote sensing research were support vector machines, neural network, random forest, and Markov random field. The paper records using SVM amounted to 675 , followed by neural networks with 571 records, then random forest (237) and Markov random field 104. These algorithms had been applied in multiple areas [36-39].

In order to visualize the co-occurrence of the most frequently-used keywords, VOSviewer [19] was adopted in our study. VOSviewer is a software tool for constructing and visualizing bibliometric networks, and it can be used to construct and visualize co-occurrence networks of important terms extracted from a body of scientific literature.

In the co-word network of the keywords in remote sensing research, fractional counting is selected to visualize the keywords co-word term map (Figure 7). Colors indicate the density of terms, ranging from blue (lowest density) to red (highest density). It can be seen that remote sensing was the core word of the network, and the prominent terms in RS research include classification, vegetation (lower middle), validation, and model (upper middle). These are all single-word terms. Among the slightly less prominent terms, we also observed various multi-word ones, such as soil moisture (upper left), hyper-spectral imagery, support vector machines (lower right), ocean color, coastal waters (middle left), synthetic aperture radar (upper right), NDVI, and vegetation index (lower left). This finding was consistent with the analysis above, and it verified the validity of our study. 


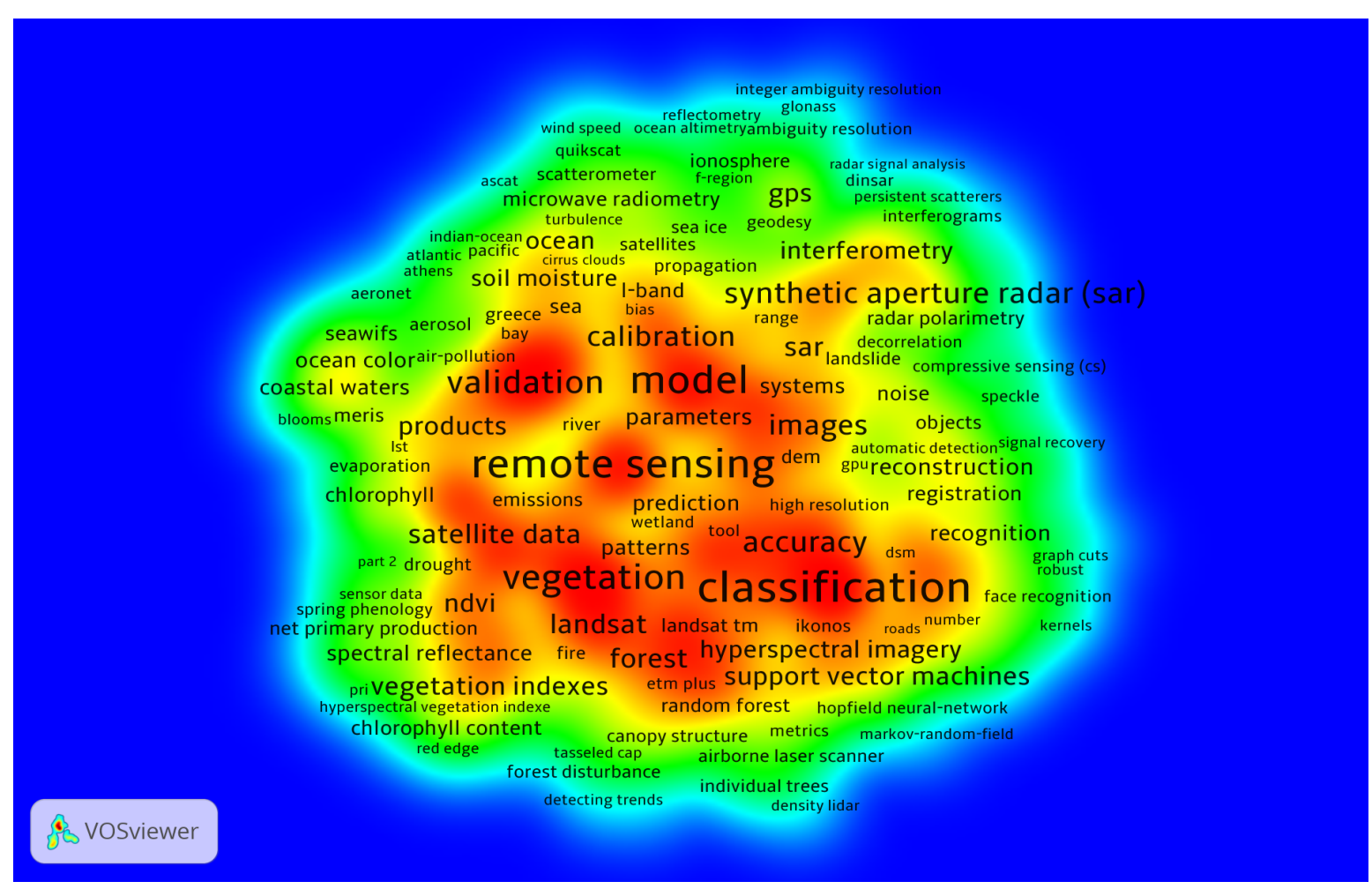

Figure 7. Co-word keywords map of remote sensing research.

(2) HCP viewpoint: There were 11,123 author's keywords and 7372 additional keywords, which covered $86 \%$ and $94 \%$ of the $5067 \mathrm{HCP}$, respectively. From the HCP viewpoint, "classification" ranked first with 584 occurrences, followed by "remote sensing" with 512 occurrences, "MODIS" (472), "model" (430), "algorithm" (339), and "vegetation" (337). The most active keywords were almost the same as from the WP viewpoint, which showed an identical trend.

We make the following conclusions from the results of the keywords' analysis:

- The usage of remote-sensing data kept increasing during 2010-2015, and "MODIS", "Landsat", "SAR", and "LiDAR" were the most used data types. It should be noted that UAVs showed a strong presence during 2010-2015.

- "Model", "algorithm", "classification", and "time series" were the prevalent technology terms during 2010-2015. "SVM" (support vector machine), "NN" (neural network), "RF" (random forest), and "MRF" (Markov random field) were the key algorithms, and new models and algorithms continued to arise. "Forest", "climate change", and "land cover/land use" were the dominant applications in remote sensing research, and remote sensing research had extended to a variety of fields.

- The WP viewpoint and the HCP viewpoint showed identical trends in hotspot issues and data usage habits.

\section{Conclusions}

Significant remote sensing research points in the SCI database were obtained by bibliometric analysis. This study provided two perspectives on the global research trends in remote sensing studies during 2010-2015. With the development of SCI, remote sensing research continually grew during 2010-2015, and the speed of growth will increase. It can be predicted that the number of scientific publications on remote sensing research will continue to grow quickly in the future. The results indicated the following conclusions. 
(1) The number of articles almost doubled during 2010-2015.

(2) Environmental sciences was the most attractive subject category with the highest CPP both from the WP viewpoint and the HCP viewpoint.

(3) The International Journal of Remote Sensing was the most productive journal during 2010-2015; however, Remote Sensing of Environment ranked first in the HCP viewpoint, followed by IEEE Transactions on Geoscience and Remote Sensing. The WP published in the high-influence journals (IF $>=2.075$ ) accounted for $44.3 \%$.

(4) Both the WP viewpoint and the HCP viewpoint showed that remote sensing research was concentrated mostly in European countries, North American countries, and East Asia. We can conclude that the economic level had a great impact on the scientific productivity.

(5) The productive ranking of countries was headed by the U.S. both from the WP viewpoint and the HCP viewpoint, but the highest CPP of the ICA occurred in Portugal (10.32), followed by Austria (8.2), Denmark (7.29), Spain (7.19), and Switzerland (7.16). This showed that the citation rate of articles in European countries was higher than other continents. Furthermore, the researchers in European countries paid more attention to international cooperation.

(6) CAS was the most productive institute with a lower CPP both from the WP viewpoint and the HCP viewpoint. NASA ranked first with highest CPP, followed by the German Aerospace Center (DLR) and Caltech. Although four of the most productive institutes were in China, the CPP of these four institutes was lower than other international institutes.

(7) Among the top 30 frequently-used keywords, "algorithm" and "time series" were emerging as hotspots during 2010-2015. MODIS, Landsat, AVHRR, and LiDAR were the prevailing sensors, while climate change and forest research had a significant presence.

Bibliometric analysis of our study revealed the current research status and future trends in remote sensing research. Analysis results showed that MODIS, Landsat, AVHRR, SAR, LiDAR, etc. were the most frequently-used remote sensing data, but the usage of small satellites and UAVs will give remote sensing a new appeal to scientists. It is easy to foresee that UAVs will rapidly become the preferred platform for the development of remote sensing instruments and applications. Moreover, with more small satellites launched, more scientists can perform research using smallsats data. From the aspect of technologies, the model and algorithm were the key points in remote sensing research, and mainly focused on the study of time series and classification issues. SVM, NN, RF, and MRF were the most frequently-used algorithms, but new models and algorithms also emerged during 2010-2015. Forest research, climate change, land cover/land use, and vegetation were the major applications in remote sensing, and remote sensing had extended to a variety of new fields.

With the improvement of data acquisition ability, it will become difficult to process the large amount of remote-sensing data, so it could be foreseen that future remote sensing research will be closely integrated with computer technology, and big data techniques may be adopted to process the massive remote sensing data, and new data algorithms and models will continue to emerge in the future.

Acknowledgments: This work was supported by the National Key Research and Development Program of China from MOST under Grant 2016YFB0501504, Hainan Provincial Department of Science and Technology under Grant ZDKJ2016021, the National Science Library of Chinese Academy of Sciences “Institutes capacity building projects on sustainable service of information analysis" under Grants Y3Y02900QT and the Open Research Fund project "Dynamic monitoring of remote sensing science and related disciplines development" (Y4Y00100KZ).

Author Contributions: Li Guoqing instructed Zhang Hongyue in the conception and design the study. Zhang Hongyue and Huang Mingrui collected the data and performed the study. Qing Xiuling gave many suggestions on how to collect the data and made the analysis more believable. Tian Chuanzhao provided some materials and made some corrections to the paper.

Conflicts of Interest: The authors declare no conflict of interest. 


\section{Abbreviations}

The following abbreviations are used in this manuscript:

WP Whole Publications

HCP Highly-Cited Publications

UAV Unmanned Aerial Vehicle

NP Number of Publications

TC Total Citation Times

CPP Average Number of Citations Per Paper

SCA Single-Country Articles

ICA International Collaboration Articles

SP Single-country Publication

CP International Collaboration Publication

DF Document Frequency

MODIS Moderate-Resolution Imaging Spectroradiometer

SPOT Systeme Probatoire d'Observation de la Terre

LiDAR Light Detection And Ranging

AVHRR Advanced Very High Resolution Radiometer

SVM Support Vector Machine

NN Neural Network

RF Random Forest

MRF Markov Random Field

\section{References}

1. Campbell, J.B.; Wynne, R.H. Introduction to Remote Sensing; Guilford Press: New York, NY, USA, 2011.

2. Huang, M. Literature analysis of the 34th Asian Conference on Remote Sensing. J. Remote Sens. 2014, 18, 1268-1275.

3. Helvajian, H.; Janson, S.W. Small Satellites: Past, Present, and Future; Aerospace Press: El Segundo, CA, USA, 2008.

4. Kramer, H.J.; Cracknell, A.P. An overview of small satellites in remote sensing. Int. J. Remote Sens. 2008, 29, 4285-4337.

5. Sandau, R. Status and trends of small satellite missions for Earth observation. Acta Astronaut. 2010, 66, 1-12.

6. Chen, Y.; Nasrabadi, N.M.; Tran, T.D. Hyperspectral image classification using dictionary-based sparse representation. IEEE Trans. Geosci. Remote Sens. 2011, 49, 3973-3985.

7. Tarabalka, Y.; Fauvel, M.; Chanussot, J.; Benediktsson, J.A. SVM-and MRF-based method for accurate classification of hyperspectral images. IEEE Geosci. Remote Sens. Lett. 2010, 7, 736-740.

8. Ferretti, A.; Fumagalli, A.; Novali, F.; Prati, C.; Rocca, F.; Rucci, A. A new algorithm for processing interferometric data-stacks: SqueeSAR. IEEE Trans. Geosci. Remote Sens. 2011, 49, 3460-3470.

9. Kennedy, R.E.; Yang, Z.; Cohen, W.B. Detecting trends in forest disturbance and recovery using yearly Landsat time series: 1. LandTrendr-Temporal segmentation algorithms. Remote Sens. Environ. 2010, 114, 2897-2910.

10. Pritchard, A. Statistical bibliography or bibliometrics. J. Doc. 1969, 25, 348.

11. Chiu, W.T.; Ho, Y.S. Bibliometric analysis of tsunami research. Scientometrics 2007, 73, 3-17.

12. Kostoff, R. The underpublishing of science and technology results. Scientist 2000, 14, 6.

13. Friedl, M.A.; Sulla-Menashe, D.; Tan, B.; Schneider, A.; Ramankutty, N.; Sibley, A.; Huang, X. MODIS Collection 5 global land cover: Algorithm refinements and characterization of new datasets. Remote Sens. Environ. 2010, 114, 168-182.

14. Goodchild, M.F.; Glennon, J.A. Crowdsourcing geographic information for disaster response: A research frontier. Int. J. Digit. Earth 2010, 3, 231-241.

15. Verbesselt, J.; Hyndman, R.; Newnham, G.; Culvenor, D. Detecting trend and seasonal changes in satellite image time series. Remote Sens. Environ. 2010, 114, 106-115.

16. Vinukollu, R.K.; Wood, E.F.; Ferguson, C.R.; Fisher, J.B. Global estimates of evapotranspiration for climate studies using multi-sensor remote sensing data: Evaluation of three process-based approaches. Remote Sens. Environ. 2011, 115, 801-823. 
17. Liu, X.; Zhan, F.B.; Hong, S.; Niu, B.; Liu, Y. A bibliometric study of earthquake research: 1900-2010. Scientometrics 2012, 92, 747-765.

18. Zhuang, Y.; Liu, X.; Nguyen, T.; He, Q.; Hong, S. Global remote sensing research trends during 1991-2010: A bibliometric analysis. Scientometrics 2013, 96, 203-219.

19. Perianes-Rodriguez, A.; Waltman, L.; van Eck, N.J. Constructing bibliometric networks: A comparison between full and fractional counting. J. Informetr. 2016, 10, 1178-1195.

20. Falagas, M.E.; Pitsouni, E.I.; Malietzis, G.A.; Pappas, G. Comparison of PubMed, Scopus, web of science, and Google scholar: strengths and weaknesses. FASEB J. 2008, 22, 338-342.

21. Vieira, E.; Gomes, J. A comparison of Scopus and Web of Science for a typical university. Scientometrics 2009, 81, 587-600.

22. Bakkalbasi, N.; Bauer, K.; Glover, J.; Wang, L. Three options for citation tracking: Google Scholar, Scopus and Web of Science. Biomed. Digit. Libr. 2006, 3, 7.

23. Jacsó, P. Google Scholar: The pros and the cons. Online Inf. Rev. 2005, 29, 208-214.

24. Feng, H.; Fang, S. Research on the application of Thomson Data Analyzer to analyses the patent intelligence of scientific institutions. Inf. Sci. 2008, 26, 1833-1843.

25. Niu, J.; Tang, W.; Xu, F.; Zhou, X.; Song, Y. Global Research on Artificial Intelligence from 1990-2014: Spatially-Explicit Bibliometric Analysis. ISPRS Int. J. Geo-Inf. 2016, 5, 66.

26. Liu, X.; Zhang, L.; Hong, S. Global biodiversity research during 1900-2009: A bibliometric analysis. Biodivers. Conserv. 2011, 20, 807-826.

27. Everaerts, J. The use of unmanned aerial vehicles (UAVs) for remote sensing and mapping. Int. Arch. Photogramm. Remote Sens. Spat. Inf. Sci. 2008, 37, 1187-1192.

28. Shahbazi, M.; Théau, J.; Ménard, P. Recent applications of unmanned aerial imagery in natural resource management. GISci. Remote Sens. 2014, 51, 339-365.

29. Dandois, J.P.; Olano, M.; Ellis, E.C. Optimal altitude, overlap, and weather conditions for computer vision UAV estimates of forest structure. Remote Sens. 2015, 7, 13895-13920.

30. Gini, R.; Passoni, D.; Pinto, L.; Sona, G. Use of Unmanned Aerial Systems for multispectral survey and tree classification: a test in a park area of northern Italy. Eur. J. Remote Sens. 2014, 47, 251-269.

31. Ambrosia, V.; Wegener, S.; Zajkowski, T.; Sullivan, D.; Buechel, S.; Enomoto, F.; Lobitz, B.; Johan, S.; Brass, J.; Hinkley, E. The Ikhana unmanned airborne system (UAS) western states fire imaging missions: from concept to reality (2006-2010). Geocarto Int. 2011, 26, 85-101.

32. Miřijovskỳ, J.; Langhammer, J. Multitemporal monitoring of the morphodynamics of a mid-mountain stream using UAS photogrammetry. Remote Sens. 2015, 7, 8586-8609.

33. Liu, C.C.; Chen, P.L.; Matsuo, T.; Chen, C.Y. Rapidly responding to landslides and debris flow events using a low-cost unmanned aerial vehicle. J. Appl. Remote Sens. 2015, 9, doi:10.1117/1.JRS.9.096016.

34. Skoglar, P.; Orguner, U.; Törnqvist, D.; Gustafsson, F. Road target search and tracking with gimballed vision sensor on an unmanned aerial vehicle. Remote Sens. 2012, 4, 2076-2111.

35. Gong, J.; Shi, H.; Ma, G.; Zhou, Q. A review of multi-temporal remote sensing data change detection algorithms. Int. Arch. Photogramm. Remote Sens. Spat. Inf. Sci. 2008, 37, 757-762.

36. Mountrakis, G.; Im, J.; Ogole, C. Support vector machines in remote sensing: A review. ISPRS J. Photogramm. Remote Sens. 2011, 66, 247-259.

37. Pal, M. Random forest classifier for remote sensing classification. Int. J. Remote Sens. 2005, 26, 217-222.

38. Blaschke, T. Object based image analysis for remote sensing. ISPRS J. Photogramm. Remote Sens. 2010, 65, $2-16$.

39. Atkinson, P.M.; Tatnall, A. Introduction neural networks in remote sensing. Int. J. Remote Sens. 1997, 18, 699-709.

(C) 2017 by the authors. Licensee MDPI, Basel, Switzerland. This article is an open access article distributed under the terms and conditions of the Creative Commons Attribution (CC BY) license (http:/ / creativecommons.org/licenses/by/4.0/). 